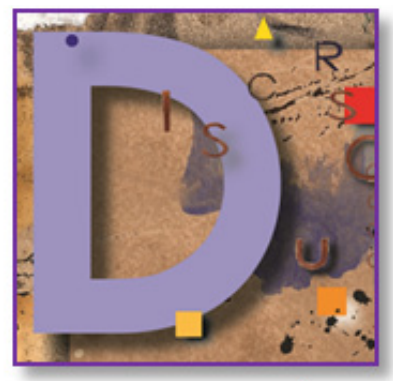

DISCURSOS CONTEMPORÄNEOS

EM

ESTUDO

ISSN 2237-7247

\section{VAN LEEUWEN, T. Discourse and practice: new tools for critical discourse analysis. New York: Oxford University Press, 2008.}

Neiva Maria Machado Soares ${ }^{1}$

Em 15 anos, Theo van Leeuwen tem escrito muitos livros e artigos sobre análise do discurso, sobre comunicação visual e sobre multimodalidade. Seu mais recente livro é The language of colour:anintroduction(2011). Atualmente, ele está trabalhando na terceira edição da obra Reading images: the grammar of visual design, com a coautoria de Gunther Kress. Esta obra será publicada em 2013. Ele também é editor da revista Comunicação visual .

A obra constitui um aparato metodológico, como o próprio nome sugere, que visa a contribuir para a análise de textos escritos ou visuais. Perpassa campos que vão desde a sociologia, àAnálise de Discurso Crítica (ADC) e à Teoria Semiótica Social da Multimodalidade (TSSM). Divide-se em nove capítulos,constituindo-se por um corpus analítico variado (livros infantis, reportagens, fotografias e brinquedos) sobre práticas do contexto escolar. Essa diversidade contribui para a análise de como as práticas sociais podem ser transformadas em discursos.

O autor considera o discurso como um recurso para a representação de práticas sociais diversas. Assim, o livro fornece ferramentas que reconstituem os discursos e que demonstram como estesreforçam e representam as práticas existentes na sociedade. Há passagens em que o autor se detém em aspectos discursivos textuais; em outras,nos semióticos. Como espera que o livro seja uma ferramenta para ADC, van Leeuwen faz uma interface com muito cuidado: primeiro, aborda o aspecto linguístico, depois, o semiótico, estabelecendo retomadas para orientar a leitura.

No primeiro capítulo, Discourse as the recontextualização of social practice, van Leeuwen discute a ideia central da obra - o discurso como uma prática social recontextualizada. Ele lembra que, do ponto de vista da $\mathrm{ADC}$, o texto deve ser estudado como representação e como interação; as práticas sociais, como modos de fazer e de regular as coisas. Coma análise de textos,segundo ele,pode-se verificar como estes se valem e se

\footnotetext{
${ }^{1}$ Doutora em Linguística pela UnB.

${ }^{2}$ Informações constante da página do autor. Disponível em:http://datasearch2.uts.edu.au/fass/staff/ listing/details. cfm? StaffId=1944. Acesso em: jan. 2012.
} 
transformam em práticas sociais ao reproduzirem o que ocorre em muitos contextos sociais. Diferentes práticas são reguladas e normatizadas pela tradição em decorrência deregras e demodelos. Ademais, van Leeuwen apresenta o conceito de discurso no sentido foucaultianodiscurso como conhecimento socialmente constituído de alguma prática social, desenvolvido em contextos sociais específicos e de forma apropriada para estes. Discurso é empregado como representação das práticas sociais nos textos que se constituem de: participantes, ações, modos de performance, condições, estilo, tempo e local.A cadeia de recontextualização de uma prática social engloba elementos linguísticos e nãolinguísticos.Os tipos de transformação tomam lugar no processo de recontextualização pela substituição de elementos linguísticospelo apagamento, pela reorganização e pela adição de um elemento à prática social. $\mathrm{O}$ capítulo descreve como os elementos das práticas sociais podem e são transformados em processo de recontextualização. Gramáticas de recontextualização mostram como a regulação ou a legitimação da prática social pode ser representada nos discursos. Finalmente, van Leeuwen ressalta que outros modos semióticos podem ser recontextualizados nas práticas sociais.

O segundo capítulo, Representação dos atores sociais,versasobre a forma como os participantes das práticas sociais podem ser representados linguisticamente no discurso. A esse tema, o autor dá maior relevânciaretomando-ono Capítulo8 e expandindo-o na forma de representação visual. Van Leeuwen considera que o ator social pode ser agente ou paciente; pode ser representado de forma pessoal, impessoal, individual ou coletiva.

A agência é um conceito sociológico de grande importância para a ADC. A representação linguística dos atores sociais pode ser de relevância sociológica e crítica. Para o autor, se a ADC, na investigação da agência, detiver-se mais nos aspectos linguísticos, pode levar à neglicência dessa questão porque não há nenhumajustepuroentre categorias linguísticas e sociológicas. As categorias propostas para investigar os participantes das práticas sociais devem ser vistas como pan-semióticas, pois o significado está relacionado à cultura. Van Leeuwen firma que uma dada cultura não tem sua própria maneira de representar o mundo social, mas de mapear os diferentes modos semióticos, dentro dessa ordem, descrevendo o que pode ser realizado verbal e visualmente. Dessa forma, com o incremento da representação visual em vários contextos, torna-se urgente à $\mathrm{ADC}$ responder a questões críticas com relação à representaçao verbal e visual. Van Leeuwen considera a exclusão importante para a análise, pois todas as práticas envolvem um conjunto de atores sociais que podem ser inseridos ou excluídos do texto (linguístico). Os atores sociais podem ser retratados de forma específica, como uma classe de indivíduos, ou de forma genérica, como pessoas comuns. Quanto à assimilação, esta se dá pela agregação e pela coletivização. A individualidade relaciona-se à singularidade; a assimilação, à pluralidade. A associação e a dissociaçãosão formadaspor e com atores sociais que não são indicados no texto; a indeterminação e a diferenciação, pelosatores anônimos; a nominação e a categorização, pela identidade; aocupação e a identificação, pelos nomes que denotam ocupação, atividade, gênero. A funcionalização e a idenficação pelos atores sociais são referidas em termos de sua atividade. A classificação é constituída pela idade, pela classe, pelo sexo, pela cor, pela raça. Os atores podem ser retratados pela personalização e pela impersonalização. A sobredeterminação ocorre quando os participantes são representados como participando, ao mesmo tempo, de mais de uma prática social. Van Leeuwen ressalta que a rede de representação dos atores sociais traz juntoo que os linguístas tendem a manter separado, envolve número de sistemas distintos: trasitividade, referência, grupos nominais, figuras retóricas, todos envolvidos na realização da representação dos atores sociais. 
No terceiro capítulo, Representação da ação social, van Leeuwen questiona sobre quais são as maneiras nas quais a ação social é representada no discurso. Para responder,ele apresenta um esquema descritivo para ADC dos modos de representação da ação social utilizando categorias críticas e sociossemânticas tais como objetivação e naturalização em realizações gramaticais e retóricas. Van Leeuwen trabalha com a teoria da transitividade de Halliday e com as metáforas gramaticais.Segundo ele, nas categorias objetivização e descritivização, as ações e as reações podem ser ativadas (por grupos verbais); podem ser representadas dinamicamente ou desativadas (por nominalização); podem ser representadas estaticamente, como se fossem entidades ou qualidades antes que processos dinâmicos. Na deagencialização, ações e reações podem ser agencializadas; podem ser representadas por agência humana ou deagencializadas; podem ser representadas sem agência humana, pelas forças naturais ou pelos processos inconscientes. Quanto à generalização e à abstração, o autor considera generalização como um assunto importante na ADC em relação a como o texto está relacionado, legitimado ou deligitimado, como se move dentro de uma alta escala de generalização. Generalização pode ser vista como uma forma de abstração. No caso da naturalização, a ação ou a reação é representada como um processo natural pelo significado do processo material abstrato.

O quarto capítulo, Time in Discourse, retrata o tempo no discurso e os recursos semióticos utilizados para representar o ritmo das práticas sociais, assim como as ferramentas sociossemânticas. Aborda a relação do tempo e a maneira como as pessoas falam sobre o tempo conectado com formas simbólicas, como a música, além do papel do tempo na vida e nas instituições. Linguisticamente, o tempo é realizado em termos da duração das atividades. Ele pode ser sicronizado com outras atividades sociais, pode ser natural, mecânico, pontual, exato e inexato, único, durativo, planejado, orçado, transformado. O tempo é diferente dependendo da classe social e do poder. Professores, nos textos analisados, são retratados como tendo o controle do tempo.

O quinto capítulo, Space in discourse, discorre sobre a representação do espaço no discurso e na imagem visual. No ponto de vista de van Leeuwen, o espaço deriva e está relacionado diretamente com a ação social, com o uso que fazemos do espaço em nossas práticas sociais. Para o autor, a análise crítica não deve ignorar o papel fundamental do espaço na conexão das práticas sociais. $\mathrm{O}$ foco está na construção do espaço no discurso. O discurso sobre o espaço fornece entendimento normativo do espaço e de seu uso no controle das práticas sociais. Linguisticamente, as posições são representadas por expressões circunstanciais. Visualmente, posições são realizadas pelas imagens, pelo plano e pelo cenário. A questão discursiva do espaço social pode ser vista como uma indicação de onde e com que arranjo espacial as coisas acontecem e pode ser seletiva, indicando as funções e os significados dos espaços. O espaço pode ser subjetivo ou objetivo e pode ser agente também. Considerando o corpus analisado, o espaço da sala de aula tem um papel importante, tornando-se um agente no sistema de ensino, bem como o lugar do professor na sala confere a este o papel de agente constituído de poder.

O sexto capítulo, A construção discursiva da legitimação, apresenta as quatro maiores categorias de legitimação. Van Leeuwen espera que elas contribuam coma análise crítica da construção da legitimação no discurso e com a reflexão dos problemas relacionados à legitimação hoje. Essas categorias já foram utilizadas por Fairclough no livro Analysing discourse: textual analysis for social research (2003). Autorização refere-se à autoridade, à lei, 
às pessoas investidas de autoridade institucional. Tem relação com o costume (tradição), com a autoridade (pessoal, impessoal) e com a recomendação (expert, modelo).Avaliação moral, por sua vez, refere-se à legitimação pela recorrência a sistemas de valor. Relaciona-se à avaliação, à abstração (modos abstratos, nomes) e à comparação. Racionalização refere-se à legitimação pela referência aos objetivos e aos usos da ação social institucionalizada e do conhecimento que a sociedade tem construído para dotá-los com valor cognitivo. A racionalização pode ser instrumental ou teórica. A mythopoesis se refere à legitimação transmitida pelas narrativas. $\mathrm{O}$ costume legitima ações. Quanto à legitimação e ao contexto, van Leeuwen afirma que um simples texto pode invocar muitos discursos diferentes e até contraditórios, como o da medicina,o da religião, o do populismo,o do feminismo e o do racismo, refletindo, assim, a crise da legitimação. $\mathrm{O}$ autor afirma, ainda, que necessitamos considerar não apenas a legitimação, mas também e, especialmente, a intrincada conexão entre as práticas sociais e os discursos que as legitimam. Van Leeuwen propõe alguns questionamentos: por que as práticas sociais existem? Por que elas têm certas formas? Qual é a intenção ao dar à escola a forma que ela tem em nossa sociedade?

No sétimo capítulo, O discurso e a construção de um propósito, van Leeuwen analisacomo os objetivos das práticas sociais são construídos, interpretados e negociados. Tomando como referência o texto Meu primeiro dia na escola, ele afirma que o propósito de as crianças irem à escola é aprender a ler e a escrevere questiona se isso é legítimo. A construção do propósito está relacionada, mas não idêntica, à construção da legitimação.A legitimação não é inerente à ação, mas discursivamente construída. A construção dos propósitos das práticas sociais como ação se constrói de uma maneira em um contexto e em outro, não.Após analisar um corpus de 4 textos com a temáticaThe firstdayatschool,van Leeuwen conclui que: professores usam métodos e técnicas de experts; há diferenças na distribuição social dos textos; as ações são tratadas dependendo da classe social das crianças; crianças devem seguir o sistema; nos textos de publicação em massa, nem crianças nem pais são representados como engajados na ação escolar. Assim, a distribuição discursiva da intencionalidade tem tudo a ver com a distribuição do poder nas práticas sociais concretas dasociedade.

No oitavo capítulo, Representação visual dos atores sociais, van Leeuwen adapta um modelo de análise dos atores sociais que apresentou no Capítulo2 para o domínio da comunicação visual e o aplica para a representação dos others nos meios de comunicação ocidental. Os atores sociais podem ser os participantes nas orações, mas nem todos os participantes são atores. Existem escolhas para representá-los, como pode ser verificado, na sequência, pelas categorias propostas. Em muitos gêneros, imagens continuam a mostrar imagens estereotipadas e diminuídas de negros. Para a análise da imagem e do viewer, três dimensões são consideradas: distância social, relação social e interação social, que se relacionam a comoaspessoas são representadas, descritas ou narradas pelo viewer. Consideram-se, por isso, as relações interpessoais. Quanto à distância: perto (plano fechado) - próximo; alguém de nós-; longe (plano aberto)- distante;pessoas estranhas. Quanto à relação:ângulo frontal - envolvimento-; ângulo vertical - acima, abaixo ou na linha dos olhos-; ângulo oblíquo- objetividade. Quanto à interação: a pessoa representada olha para o viewer (endereçamento direto); não olha para o viewer (endereçamento indireto). Quanto à representação das relações de poder, van Leeuwen sugere que o ângulo alto demonstra o poder do observador; o olhar no mesmo nível, igualdade. Para a descrição dos participantes no discurso, as categorias investigam como são retratados, inseridos ou não em grupos, e 
denominados social e culturalmente. A categorização dos participantes acontece pela inclusão ou pela exclusão dos deles. A exclusão significa a não representação de pessoas em todos os contextos em que estão representadas. Nainclusão, os participantes podem ser retratados como: agente/ paciente; específico/genérico; indivíduo/grupo.O específico torna a pessoa única; o genérico leva a pessoa a desaparecer, pela categorização cultural ou pela biológica. Van Leeuwen alega que essas estratégias podem ocorrer em diferentes combinações e graus em histórias de opressão, de racismo, de diferença de classes, que levam ao estereótipo racial, ao prejuízo cultural e étnico representados nos discursos.

O nono e último capítulo, Representing social actorswithtoys, destina-se à representação de atores sociais com brinquedosvistos como recursos semióticos para representação de papéis sociais e de identidades. Van Leeuwen explica que o Playmobil oferece perspectiva específica em gênero e em raça. Algumas categorias já apresentadas são retomadas para análisede brinquedos. Quanto aos papéis, às identidades e aos sentidos, odesign do brinquedo pode ser visto como representação simbólica de papéis e de identidades. Os papéis dos brinquedos, para as crianças, têm a ver com o que eles fazem ou não: identidade, com características faciais, cor da pele, assim como o tamanho e a cor do cabelo; significados, com a designação dos brinquedos para representar papel social e identidade "realista". O modo como osistema de brinquedos é denominado e o mercado fornecem modelos estruturados da sociedade por meio de princípios organizados. Com base na análise,van Leeuwen afirma que esses objetos são uma mistura de permissão e de repressão já na infância, porém, ele vê o Lego como uma repressão menor, pois a sua montagem livre.

Noscapítulosda obra, vemos que muito do que o autor propõe como categorias analíticas já se encontram em outros livros, principalmente em Reading images: the grammarof visual design (1996), porém há uma expansão dessas categorias com as respectivas sugestões de análise, principalmente com o cruzamento da ADC. Em algumas passagens, o autor ressalta que não se deterá nas questões linguísticas, mas, sim, nas visuais. Contudo, ele faz analogias entre as questões linguísticas e as semióticas, explicitando que certa categoria no aspecto linguístico se dá por advérbios; no semiótico, pelos espaços, pelo plano, por exemplo.

O livro é uma ótima ferramenta não apenas para analistas do discurso, mas também para aqueles de áreas afins, pois fornece um aparato de categorias, principalmente visuais, que podemser mais trabalhadas e entendidas por profissionais de linguagemna investigação decomo as práticas sociais moldam, constituem e retratam a nossa ação social. 


\section{Referências}

FAIRCLOUGH, N. Analysing discourse: textual analysis for social research. Londres: Routledge, 2003.

KRESS, G.; VAN LEEUWEN, T. Reading images: the grammar visual design. London; New York: Routledge, 1996.

VAN LEEUWEN, T. The language of colour: an introduction. London: Routledge, 2011. 